\title{
Genetic Analysis of Resistance to Pyrenophora tritici-repentis Races 1 and 5 in Tetraploid and Hexaploid Wheat
}

\author{
P. K. Singh, M. Mergoum, S. Ali, T. B. Adhikari, and G. R. Hughes
}

First and second authors: Department of Plant Sciences, 166-Loftsgard Hall, North Dakota State University, Fargo 58105; third and fourth authors: Department of Plant Pathology, 306-Walster Hall, North Dakota State University, Fargo 58105; and fifth author: Department of Plant Sciences, 51-Campus Drive, University of Saskatchewan, Saskatoon, SK, S7N5A8, Canada. Accepted for publication 25 February 2008.

\begin{abstract}
Singh, P. K., Mergoum, M., Ali, S., Adhikari, T. B., and Hughes, G. R. 2008. Genetic analysis of resistance to Pyrenophora tritici-repentis races 1 and 5 in tetraploid and hexaploid wheat. Phytopathology 98:702-708.

Tan spot of wheat, caused by the fungus Pyrenophora tritici-repentis, is a destructive disease worldwide that can lead to serious losses in quality and quantity of wheat grain production. Resistance to multiple races of $P$. tritici-repentis was identified in a wide range of genetically diverse genotypes, including three different species Triticum aestivum (AABBDD), T. spelta (AABBDD), and T. turgidum (AABB). The major objectives of this study were to determine the genetic control of resis-

analyzed for the allelism tests and/or inheritance studies. Plants were inoculated at the two-leaf stage under controlled environmental conditions and disease reaction was assessed based on lesion-type rating scale. A single recessive gene controlled resistance to necrosis caused by $P$. tritici-repentis race 1 in both tetraploid and hexaploid resistant genotypes. The lack of segregation in the inter- and intra-specific crosses between the resistant tetraploid and hexaploid genotypes indicated that they possess the same genes for resistance to tan necrosis and chlorosis induced by $P$. tritici-repentis race 1 . A single dominant gene for chlorosis in hexaploid wheat and a single recessive gene for necrosis in tetraploid wheat, controlled resistance to $P$. tritici-repentis race 5 .
\end{abstract} tance to $P$. tritici-repentis races 1 and 5 in 12 newly identified sources of resistance. The parents, $\mathrm{F}_{1}, \mathrm{~F}_{2}$, and $\mathrm{F}_{2: 3}$ or $\mathrm{F}_{2: 5}$ families of each cross were

Tan spot, a foliar disease of durum and common wheat, is caused by the fungus Pyrenophora tritici-repentis (Died.) Drechs. This fungus on susceptible durum and common wheat induces two distinct symptoms; tan necrosis and chlorosis. On an average, tan spot causes 5 to $15 \%$ yield losses; however, it can cause up to $50 \%$ yield loss under conditions favorable for disease development $(2,20)$. Tan spot also adversely affects the quality of grain by causing grain shrivelling, dark smudge, and black point $(2,9)$. Recent increases in the severity and incidence of tan spot have been attributed to changes in cultural practices such as shifts from conventional tillage and stubble burning to conservation tillage systems, shorter crop rotations, continuous wheat cultivation, and use of susceptible wheat cultivars $(2,9)$. Adoption of a number of cultural practices in association with application of fungicides is effective in controlling tan spot but they have their limitations. Growing resistant cultivars is the most practical, environmentally safe, effective, and economical means of controlling this disease $(2,20)$.

Currently, eight races of $P$. tritici-repentis have been identified based on their ability to induce necrosis and/or chlorosis on a set of differential cultivars (17). To date, three host-specific toxins (e.g., Ptr ToxA, Ptr ToxB, and Ptr ToxC) produced by the tan spot fungus have been identified and characterized. Genetic studies have established that the same gene controls sensitivity to the toxins and susceptibility to their producer races $(3,12)$.

Evaluation of germplasm could lead to identification of potential donors for a given trait. Information coming out of genetic studies reveals which germplasm and breeding strategy is to be adopted to develop cultivars containing the desired traits. Various

Corresponding author: M. Mergoum; E-mail address: Mohamed.Mergoum@ndsu.edu

doi:10.1094/PHYTO-98-6-0702

(c) 2008 The American Phytopathological Society
Additional keywords: host resistance, Triticum species. host-pathogen interaction studies on tan spot of wheat have reported resistance to be inherited qualitatively $(1,15,22)$ or quantitatively $(4,7,18)$. The same single recessive gene conditioning resistance to necrosis induced by $P$. tritici-repentis races 1 and 2 , in both tetraploid and hexaploid wheat, is mapped on the long arm of chromosome $5 \mathrm{~B}$ and designated as tsn1 $(1,6)$. The relationship between other resistance genes for tan spot in tetraploid and hexaploid wheat is still unknown.

Singh et al. (21) mapped the gene, $t s n 2$, controlling resistance to necrosis induced by $P$. tritici-repentis race 3 in tetraploid wheat to the long arm of chromosome 3B. Tadesse et al. (27) identified single recessive genes, $t s n 3$ and $t s n$-synl, effective against tan spot caused by $P$. tritici-repentis race 1 on chromosome 3D in the hexaploid synthetic wheat lines XX41 and XX110, respectively. Additionally, they also observed a dominant gene, designated Tsn-syn2, on chromosome 3D in the synthetic line XX45. In a recent report, Tadesse et al. (28) reported resistance to tan spot induced by $P$. tritici-repentis race 1 in the hexaploid resistant genotype Salamouni to be located on chromosome $3 \mathrm{~A}$ and designated the gene as $t s n 4$. Singh et al. (25) reported that a single gene located on chromosome $3 \mathrm{~B}$, designated $t s n 5$, controls resistance to necrosis induced by $P$. tritici-repentis race 5 in tetraploid wheat.

Working with hexaploid wheat, Effertz et al. (3) mapped the locus, $t s c l$, conditioning insensitivity to chlorosis caused by toxin Ptr ToxC (P. tritici-repentis race 1$)$ to the short arm of chromosome 1A. Faris et al. (7) reported that resistance to chlorosis caused by $P$. tritici-repentis race 3 in hexaploid wheat was quantitative with a major quantitative trait loci (QTL) located on chromosome 1A. Further, Singh and Hughes (23) confirmed that resistance to chlorosis caused by $P$. tritici-repentis races 1 and 3 in hexaploid wheat was controlled by the same gene. Friesen and Faris (10), using a hexaploid wheat population, identified the Ptr ToxB insensitivity gene, $t s c 2$, at the distal tip of the short arm of 
chromosome 2B. This gene accounted for $69 \%$ of the phenotypic variation caused by $P$. tritici-repentis race 5. Faris and Friesen (8), studying hexaploid wheat, for the first time observed race nonspecific QTLs on chromosome arms 1BS and 3BL effective against $P$. tritici-repentis races $1,2,3$, and 5 .

Singh et al. (24) screened 975 accessions of wheat and its related species and identified new sources of resistance effective against $P$. tritici-repentis races $1,2,3$, and 5. The objectives of this study were to (i) determine the genetic basis of resistance to $P$. tritici-repentis races 1 and 5 in the newly identified sources of resistance coming from different Triticum species including synthetic wheat, (ii) clarify through allelic studies if these uncharacterized resistant sources possess resistance genes not identified previously, and (iii) determine the relationship between resistance genes in tetraploid and hexaploid wheat.

\section{MATERIALS AND METHODS}

Population development. A total of 17 genotypes were selected for this study based on their genetic make-up and reaction to $P$. tritici-repentis races 1 and 5 (Table 1). These genotypes included seven synthetic hexaploid wheat genotypes namely, Synthetic Hexaploid Elite (SHE) \#9, SHE \#25, SHE \#67, SHE \#85, SHE \#89, Altar Synthetic, and Septoria Synthetic \#57; seven hexaploid wheat genotypes, Kenyon, Katepwa, 98W1147, Erik, CIMMYT Line \#18, Intros Line \#7, and 92MREHTR 28B; one hexaploid spelt wheat, 2000 Spelt \#20; one tetraploid accession, T. turgidum \#283 (PI352519); and the durum cultivar Coulter. These genotypes were selected based on the findings of Singh et al. (24). Twenty cross populations including 13 resistant/ susceptible (R/S), 5 resistant/resistant (R/R), and 2 susceptible/ susceptible $(\mathrm{S} / \mathrm{S})$, were made using the 17 selected genotypes. Each $F_{1}$ plant grown to produce $F_{2}$ seed was harvested separately. The individual $F_{2}$ populations of each cross were tested for disease reaction to eliminate nonhybrid populations. The $\mathrm{F}_{2}$ plants were grown to produce $F_{2: 3}$ families. Advance generations $\left(F_{2: 5}\right.$ families) were produced by single seed descent in each of the crosses studied.

To study the inheritance and allelic relationship of the resistance genes for tan spot, the parents, $F_{1}, F_{2}$, and $F_{2: 3}$ or $F_{2: 5}$ families were screened individually with $P$. tritici-repentis race 1 or 5. Depending upon the cross, 7 to $9 F_{1}$ plants per cross and $F_{2}$ populations ranging from 76 to 269 plants per cross were screened. At least 70 families per cross were tested for the genetic studies. A family size of 16 to 18 plants was used for the genetic studies. This gave a $99 \%$ probability of being able to distinguish between a segregating and a nonsegregating family assuming a single gene controlled resistance (13).

Disease assessment. The conidial inoculum was produced using a modification of the method of Lamari and Bernier (14). The isolates Ptr D-2000-HT VI-5 (P. tritici-repentis race 1$)$ and Ptr DW-13 (P. tritici-repentis race 5) were used for inoculum production. Additionally, the cross $T$. turgidum \#283/Coulter was screened with $P$. tritici-repentis race 2 isolate Ptr 86-124. The inoculum of $P$. tritici-repentis races 1,2 , and 5 was obtained by placing $0.5-\mathrm{cm}$-diameter dried mycelial plugs of the isolate, previously stored at $-20^{\circ} \mathrm{C}$, on $10-\mathrm{cm}$ petri plates containing V8potato dextrose agar (PDA) (150 ml of V8-juice, $10 \mathrm{~g}$ of PDA, $10 \mathrm{~g}$ of agar, $3 \mathrm{~g}$ of $\mathrm{CaCO}_{3}$, and $850 \mathrm{ml}$ of distilled water). These cultures were incubated in the dark at 20 to $22^{\circ} \mathrm{C}$ for 6 days. The plates were then flooded with sterile distilled water and the mycelium was flattened with the base of a sterile test tube. Excess water was decanted from the dishes and the plates were incubated under continuous light at 22 to $24^{\circ} \mathrm{C}$ for 2 days followed by 1 day in the dark in an incubator at $16^{\circ} \mathrm{C}$ to induce conidiophore and conidia production, respectively. The plates were flooded with sterile distilled water and the conidia were dislodged with a camel-hair brush. Spore concentration was measured with a haemocytometer and adjusted to 3,000 conidia per $\mathrm{ml}$ before inoculation. In order to reduce surface tension, 2 drops of Tween 20 (polyxyethlene sorbitan monolaurate) were added per liter of the spore suspension.

To optimize uniform emergence, seeds were pregerminated and seeds at a similar stage of germination were planted in 6-indiameter pots containing soilless mix (Redi-Earth, W.R. Grace and Co. of Canada Ltd., Ajax, ON, Canada). Appropriate checks including the resistant and susceptible parents used in the development of the cross were included in each test to verify the validity of the race and inoculation process. For the genetic studies, nine seeds per pot were planted. All disease tests were

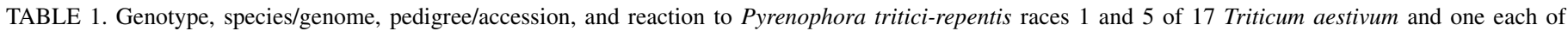

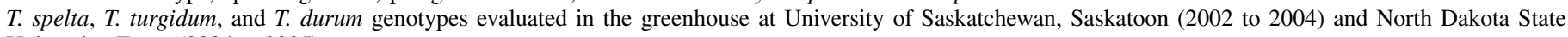
University, Fargo (2004 to 2005)

\begin{tabular}{|c|c|c|c|c|c|c|}
\hline \multirow[b]{2}{*}{ Genotype } & \multirow[b]{2}{*}{ Species/genome } & \multirow[b]{2}{*}{ Pedigree/accessions } & \multicolumn{2}{|c|}{ Race 1} & \multicolumn{2}{|c|}{ Race 5} \\
\hline & & & Necrosis & Chlorosis & Necrosis & Chlorosis \\
\hline Synthetic Hexaploid Elite \#9 & T. aestivum/ABD & Altar 84/A. tauschii (211) & Resistant $^{\mathrm{a}}$ & Resistant & Resistant & Resistant \\
\hline Synthetic Hexaploid Elite \#25 & T. aestivum/ABD & Altar 84/A. tauschii (224) & Resistant & Resistant & Resistant & Resistant \\
\hline Synthetic Hexaploid Elite \#67 & T. aestivum/ABD & Snipe/YAV79//Dack/Teal/3/A. tauschii (629) & Resistant & Resistant & Resistant & Resistant \\
\hline Synthetic Hexaploid Elite \#85 & T. aestivum/ABD & Ceta/A. tauschii (174) & Resistant & Resistant & Resistant & Resistant \\
\hline Synthetic Hexaploid Elite \#89 & T. aestivum/ABD & STY-US/Celta//Pals/3/SRN5/4/A.tauschii (502) & Resistant & Resistant & Resistant & Resistant \\
\hline Septoria Synthetic \#57 & T. aestivum/ABD & $\mathrm{BCN} / / \mathrm{GAN} / A$. squarrosa $(408)$ & Resistant & Resistant & Resistant & Resistant \\
\hline ALTAR Synthetic & T. aestivum/ABD & Altar 84*5/A. squarrosa (219)//YACO & Resistant & Resistant & Resistant & Resistant \\
\hline 92MREHTR 28B & T. aestivum/ABD & Car853/Coc//Vee'S'/3/E7408/Pam'S'//Hor & Resistant & Resistant & Resistant & Resistant \\
\hline CIMMYT Line \#18 & T. aestivum/ABD & Unknown (origin Mexico) & Resistant & Resistant & Resistant & Resistant \\
\hline INTROS Line \#7 & T. aestivum/ABD & Unknown (origin Mexico ) & Resistant & Resistant & Resistant & Resistant \\
\hline Katepwa & T. aestivum/ABD & $\begin{array}{l}\text { Neepawa*6/RL-2938/3/Neepawa*6// } \\
\text { CI-8154/2*Frocor }\end{array}$ & Susceptible ${ }^{b}$ & Resistant & Resistant & Susceptible \\
\hline Kenyon & T. aestivum/ABD & Neepawa*5/Buck Manantial & Susceptible & Resistant & Resistant & Susceptible \\
\hline 98W1147 & T. aestivum/ABD & HY413/93FHB\#21//ID3775 & Susceptible & Resistant & Resistant & Resistant \\
\hline 2000 Spelt \#20 & T. spelta/ABD & PI348771/Oberkulm & Resistant & Resistant & Resistant & Resistant \\
\hline Triticum turgidum \#283 & T. turgidum/AB & PI352519 & Resistant & Resistant & Resistant & Resistant \\
\hline Coulter & T. durum/AB & DT-188/Dt-224//DT-182 & Susceptible & Resistant & Susceptible & Resistant \\
\hline Erik (Check) & T. aestivum/ABD & Kitt/2/Waldron/Era & Resistant & Resistant & Resistant & Resistant \\
\hline 6B-365 (Check) & T. aestivum/ABD & Unknown & Resistant & Susceptible & Resistant & Resistant \\
\hline 6B-662 (Check) & T. aestivum/ABD & Unknown & Resistant & Resistant & Resistant & Susceptible \\
\hline Glenlea (Check) & T. aestivum/ABD & Pemina*2/Bage/2/CB100 & Susceptible & Resistant & Resistant & Resistant \\
\hline
\end{tabular}

a Genotype showing resistant reaction and a rating of 1 to 2 on a 1-to-5 lesion-type scale.

${ }^{b}$ Genotype showing susceptible reaction and a rating of 3 to 5 on a 1-to-5 lesion-type scale. 
conducted using a completely randomized design with two replicates. Using a hand sprayer, plants at the two-leaf stage were sprayed until runoff with the conidial suspension of the race tested. Following inoculation, the seedlings were incubated for $24 \mathrm{~h}$ maintaining continuous leaf wetness in a mist chamber located in a growth room at $22 / 17^{\circ} \mathrm{C}$ (day/night) with a 16 -h photoperiod and then returned to benches in the same growth room. Eight days after inoculation, the seedlings were rated for disease reaction based on the 1-to-5 lesion-type rating scale developed by Lamari and Bernier (14), with plants having ratings of 1 and 2 considered resistant and those with ratings of 3 to 5 classified as susceptible.

Statistical analysis. Segregation data observed for the $F_{2}$ plants and $F_{2: 3}$ and $F_{2: 5}$ families were analyzed using the chi-square test for goodness-of-fit to various genetic models to determine the number of genes controlling resistance to tan spot of wheat (26).

\section{RESULTS}

Reaction of the 17 selected genotypes to $P$. tritici-repentis races 1 and 5 were consistent in all tests. Kenyon, 98W1147, Katepwa, and Coulter were susceptible showing necrotic symptoms but were resistant to chlorosis induced by $P$. tritici-repentis race 1 (Table 1). All the remaining 12 genotypes were resistant to both the necrosis and chlorosis components of tan spot induced by P. tritici-repentis race 1. Kenyon and Katepwa showed chlorosis while Coulter exhibited necrotic symptoms upon inoculation with $P$. tritici-repentis race 5. All the other genotypes were resistant to $P$. tritici-repentis race 5 (Table 1). The checks genotypes; Erik, Glenlea, 3B-365, and 6B-662, reacted as expected upon inoculation with either $P$. tritici-repentis race 1 or race 5 (16).

Genetics of resistance to $P$. tritici-repentis race 1: Inheritance studies. All $13 \mathrm{R} / \mathrm{S}$ crosses studied were observed to segregate for the necrosis component of tan spot caused by $P$. triticirepentis race 1 and segregation did not occur for the chlorosis component. All the $\mathrm{F}_{1}$ plants of the R/S cross among tetraploid wheat were susceptible, indicating that resistance to necrosis was recessive in tetraploid wheat (Table 2). In the inter-specific R/S cross between T. turgidum \#283 (tetraploid) and 98W1147 (hexaploid), all $F_{1}$ plants were susceptible. The two susceptible hexaploid genotypes, Kenyon and 98W1147, were crossed with a diverse set of resistant hexaploid parents including synthetic and spelt wheat; however, all $\mathrm{F}_{1}$ plants of these R/S crosses were susceptible indicating resistance to necrosis induced by $P$. triticirepentis race 1 in the hexaploid wheat was controlled by recessive gene(s).

The $\mathrm{F}_{2}$ generation of the $13 \mathrm{R} / \mathrm{S}$ inter-and intra-specific crosses segregated in a 1 resistant: 3 susceptible ratio, indicating that a single gene controlled resistance and confirming that resistance to necrosis was recessive in all crosses studied (Table 2). The $F_{2: 3}$ families of all $\mathrm{R} / \mathrm{S}$ crosses segregated in the ratio 1 homozygous resistant:2 segregating:1 homozygous susceptible, thus confirming the hypothesis of monogenic control of resistance to necrosis in tetraploid wheat, hexaploid wheat, and an inter-specific cross between tetraploid and hexaploid wheat (Table 3).

Allelism studies. All the 16 parents involved in development of the 19 crosses studied with $P$. tritici-repentis race 1 , were resistant to chlorosis (Table 1). In each of the 19 crosses, which were $R / R$ crosses for segregation to chlorosis by $P$. tritici-repentis race 1 , all $F_{1}$ and $F_{2}$ plants tested were resistant (Table 2). Confirmation of the lack of segregation of single-plant data was done by screening $\mathrm{F}_{2: 3}$ families of all the crosses except the cross Coulter/Kenyon. The lack of segregation for chlorosis confirms that the resistant sources from both tetraploid and hexaploid wheat shared the resistance gene(s) controlling chlorosis induced by $P$. tritici-repentis race 1 (Table 3 ).

All $F_{1}$ plants of the $R / R$ crosses of five resistant hexaploid genotypes with the resistant hexaploid check cultivar Erik were resistant to necrosis induced by $P$. tritici-repentis race 1 (Table 2). However, while most $F_{2}$ plants of these crosses were resistant, a few plants in four of the five crosses gave a moderately susceptible necrotic reaction (rating 3 ). None of the segregations of the

TABLE 2. Reaction of $F_{1}$ and $F_{2}$ plants of 19 wheat crosses to necrosis caused by Pyrenophora tritici-repentis race 1 evaluated in the greenhouse at University of Saskatchewan, Saskatoon in 2002 to 2004

\begin{tabular}{|c|c|c|c|c|c|c|c|}
\hline \multirow[b]{2}{*}{ Cross } & \multicolumn{2}{|c|}{$\mathrm{F}_{1}$} & \multicolumn{2}{|c|}{$\mathrm{F}_{2}$} & \multirow[b]{2}{*}{ Ratio tested } & \multirow[b]{2}{*}{$\chi^{2}$ value } & \multirow[b]{2}{*}{$P$ value $^{\mathrm{b}}$} \\
\hline & $\mathrm{R}^{\mathrm{a}}$ & $S$ & $\mathrm{R}$ & $\mathrm{S}$ & & & \\
\hline \multicolumn{8}{|c|}{ Resistant (hexaploid)/susceptible (hexaploid) } \\
\hline Syn. Hex. Elite \#67/98W1147 & 0 & 9 & 72 & 166 & $1: 3$ & 3.50 & 0.06 \\
\hline Syn. Hex. Elite \#85/98W1147 & 0 & 7 & 76 & 180 & $1: 3$ & 3.00 & 0.08 \\
\hline Syn. Hex. Elite \#89/98W1147 & 0 & 7 & 52 & 124 & $1: 3$ & 1.94 & 0.16 \\
\hline Intros Line \#7/Kenyon & 0 & 8 & 60 & 196 & $1: 3$ & 0.33 & 0.56 \\
\hline CIMMYT Line \#18/Kenyon & 0 & 9 & 61 & 198 & $1: 3$ & 0.29 & 0.59 \\
\hline Altar Synthetic/Kenyon & 0 & 8 & 54 & 202 & $1: 3$ & 2.08 & 0.14 \\
\hline 92MREHTR28B/Kenyon & 0 & 7 & 60 & 197 & $1: 3$ & 0.37 & 0.54 \\
\hline \multicolumn{8}{|c|}{ Resistant (tetraploid)/susceptible (tetraploid) } \\
\hline Triticum turgidum \#283/Coulter & 0 & 7 & 74 & 181 & $1: 3$ & 2.19 & 0.13 \\
\hline \multicolumn{8}{|c|}{ Resistant (tetraploid)/susceptible (hexaploid) } \\
\hline Altar Synthetic/Erik & 9 & 0 & 255 & 1 & $1: 0$ & - & - \\
\hline \multicolumn{8}{|c|}{ Resistant (tetraploid)/resistant (hexaploid) } \\
\hline T. turgidum \#283/Erik & 7 & 0 & 192 & 0 & 1:0 & - & - \\
\hline \multicolumn{8}{|c|}{ Susceptible (tetraploid)/susceptible (hexaploid) } \\
\hline Coulter/Kenyon & 0 & 8 & 0 & 168 & $0: 1$ & - & - \\
\hline
\end{tabular}

a Plants were rated on a 1-to-5 lesion-type rating scale. Plants with ratings of 1 and 2 were classified as resistant (R) and those with ratings of 3 to 5 were classified as susceptible ( $\mathrm{S}$ ).

${ }^{\mathrm{b}}$ Probability of obtaining deviations from the expected ratio by chance alone. A probability value greater than 0.05 indicates that the observed population does not differ significantly from expected hypothesis. 
$R / R$ crosses fit a ratio indicative that the resistant sources possessed different resistance genes. The $F_{1}$ and $F_{2}$ single-plant segregation data were confirmed by screening the $\mathrm{F}_{2: 3}$ families of each of these crosses. All the $\mathrm{F}_{2: 3}$ families of each of the crosses tested were homozygous resistant, thus confirming that all the six resistant parents shared the same resistance gene (Table 3). All $F_{1}$ and $F_{2}$ generations and $F_{2: 3}$ families of the cross between resistant tetraploid genotype T. turgidum \#283 and resistant hexaploid cultivar Erik did not segregate for resistance (Tables 2 and 3). This confirms that the tetraploid and hexaploid resistant geno- types studied shared the same single gene for resistance to necrosis induced by $P$. tritici-repentis race 1.

Genetics of resistance to $P$. tritici-repentis race 5: Inheritance studies. All $\mathrm{F}_{1}$ plants of the four R/S crosses among the hexaploid wheat genotypes were resistant, indicating that resistance to chlorosis caused by $P$. tritici-repentis race 5 was dominant (Table 4). The $F_{2}$ generations of the $R / S$ intra-specific crosses segregated in a 3 resistant: 1 susceptible ratio, indicating that a single gene controls resistance and confirming that resistance to chlorosis was dominant in all the crosses studied. The $\mathrm{F}_{2: 5}$

TABLE 3. Reaction of $\mathrm{F}_{2: 3}$ families of 18 wheat crosses to necrosis caused by Pyrenophora tritici-repentis race 1 evaluated in the greenhouse at University of Saskatchewan, Saskatoon in 2002 to 2004

\begin{tabular}{|c|c|c|c|c|c|c|}
\hline \multirow[b]{2}{*}{ Cross } & \multicolumn{3}{|c|}{$\mathrm{F}_{2: 3}$ families $^{\mathrm{a}}$} & \multirow[b]{2}{*}{ Ratio tested } & \multirow[b]{2}{*}{$\chi^{2}$ value } & \multirow[b]{2}{*}{$P$ value ${ }^{\mathrm{b}}$} \\
\hline & $\mathrm{R}$ & Seg & $\mathrm{S}$ & & & \\
\hline \multicolumn{7}{|c|}{ Resistant (hexaploid)/susceptible (hexaploid) } \\
\hline Syn. Hex. Elite \#9/98W1147 & 17 & 45 & 18 & $1: 2: 1$ & 1.18 & 0.56 \\
\hline Syn. Hex. Elite \#67/98W1147 & 22 & 44 & 14 & $1: 2: 1$ & 1.50 & 0.47 \\
\hline Syn. Hex. Elite \#85/98W1147 & 14 & 47 & 19 & $1: 2: 1$ & 3.05 & 0.22 \\
\hline Syn. Hex. Elite \#89/98W1147 & 17 & 45 & 18 & $1: 2: 1$ & 1.18 & 0.56 \\
\hline Sep. Syn. \#57/Kenyon & 22 & 40 & 18 & $1: 2: 1$ & 0.30 & 0.86 \\
\hline CIMMYT Line \#18/Kenyon & 14 & 44 & 22 & $1: 2: 1$ & 1.50 & 0.47 \\
\hline Altar Synthetic/Kenyon & 13 & 42 & 25 & $1: 2: 1$ & 3.13 & 0.21 \\
\hline 92MREHTR28B/Kenyon & 14 & 45 & 21 & $1: 2: 1$ & 2.45 & 0.29 \\
\hline \multicolumn{7}{|c|}{ Resistant (tetraploid)/susceptible (tetraploid) } \\
\hline Triticum turgidum \#283/Coulter & 17 & 33 & 20 & $1: 2: 1$ & 0.36 & 0.86 \\
\hline \multicolumn{7}{|c|}{ Resistant (tetraploid)/susceptible (hexaploid) } \\
\hline T. turgidum \#283/98W1147 & 20 & 36 & 14 & $1: 2: 1$ & 0.74 & 0.69 \\
\hline Altar Synthetic/Erik & 80 & 0 & 0 & 1:0:0 & - & - \\
\hline \multicolumn{7}{|c|}{ Resistant (tetraploid)/resistant (hexaploid) } \\
\hline T. turgidum \#283/Erik & 70 & 0 & 0 & 1:0:0 & - & - \\
\hline
\end{tabular}

${ }^{\text {a }}$ Plants were rated on a 1-to-5 lesion-type rating scale with families having plants with ratings of 1 and 2 classified as resistant (R), ratings of 3 to 5 as susceptible (S), and those with both resistant and susceptible plants as segregating (Seg).

${ }^{\mathrm{b}}$ Probability of obtaining deviations from the expected ratio by chance alone. A probability value greater than 0.05 indicates that the observed population does not differ significantly from expected hypothesis.

TABLE 4. Reaction of $\mathrm{F}_{1}$ and $\mathrm{F}_{2}$ plants of 11 wheat crosses to necrosis and chlorosis caused by Pyrenophora tritici-repentis race 5 evaluated in the greenhouse at University of Saskatchewan, Saskatoon (2002 to 2004) and North Dakota State University, Fargo (2004 to 2005)

\begin{tabular}{|c|c|c|c|c|c|c|c|}
\hline \multirow[b]{2}{*}{ Cross } & \multicolumn{2}{|c|}{$\mathrm{F}_{1}$} & \multicolumn{2}{|c|}{$\mathrm{F}_{2}$} & \multirow[b]{2}{*}{ Ratio tested } & \multirow[b]{2}{*}{$\chi^{2}$ value } & \multirow[b]{2}{*}{$P$ value ${ }^{\mathrm{c}}$} \\
\hline & $\mathrm{R}^{\mathrm{b}}$ & $S$ & $\mathrm{R}$ & $\mathrm{S}$ & & & \\
\hline \multicolumn{8}{|l|}{ Resistant (hexaploid)/susceptible (hexaploid) } \\
\hline Sep. Syn. \#57/Kenyon & 9 & 0 & 160 & 49 & $3: 1$ & 0.27 & 0.60 \\
\hline CIMMYT Line \#18/Kenyon & 8 & 0 & 150 & 58 & $3: 1$ & 0.92 & 0.34 \\
\hline Altar Synthetic/Kenyon & 7 & 0 & 157 & 63 & $3: 1$ & 1.55 & 0.21 \\
\hline \multicolumn{8}{|l|}{ Resistant (hexaploid)/resistant (hexaploid) } \\
\hline Altar Synthetic/Erik & 8 & 0 & 212 & 0 & $1: 0$ & - & - \\
\hline \multicolumn{8}{|l|}{ Resistant (tetraploid)/resistant (hexaploid) } \\
\hline Triticum turgidum \#283/Erik & 9 & 0 & 221 & 0 & 1:0 & - & - \\
\hline \multicolumn{8}{|l|}{ Susceptible (tetraploid)/susceptible (hexaploid) } \\
\hline Coulter/Katepwa & 0 & 9 & 13 & 63 & $3: 13$ & 0.13 & 0.72 \\
\hline \multicolumn{8}{|l|}{ Resistant (tetraploid)/susceptible (tetraploid) inoculated by race 5} \\
\hline
\end{tabular}

${ }^{a}$ Necrotic reaction of $F_{1}$ and $F_{2}$ plants of cross Triticum turgidum \#283/Coulter to races 2 and 3 is presented.

${ }^{\mathrm{b}}$ Plants were rated on a 1-to-5 lesion-type rating scale. Plants with ratings of 1 and 2 were classified as resistant (R) and those with ratings of 3 to 5 were classified as susceptible (S).

${ }^{\mathrm{c}}$ Probability of obtaining deviations from the expected ratio by chance alone. A probability value greater than 0.05 indicates that the observed population does not differ significantly from expected hypothesis. 
families of all four R/S crosses segregated in the ratio 7 homozygous resistant:2 segregating:7 homozygous susceptible, thus confirming the hypothesis of monogenic control of resistance to chlorosis induced by $P$. tritici-repentis race 5 in hexaploid wheat (Table 5). In previous studies, resistance to necrosis induced by $P$. tritici-repentis races 3 and 5 in the tetraploid cross T. turgidum \#283/Coulter was reported to be controlled by single recessive genes $(21,25)$. In this study, the same cross was additionally screened with $P$. tritici-repentis race 2 and the segregation of the $\mathrm{F}_{1}$ and $\mathrm{F}_{2}$ generations and $\mathrm{F}_{2: 5}$ families indicated that a single recessive gene control (Tables 4 and 5).

Allelism studies. All $F_{1}$ and $F_{2}$ generations of the four $R / R$ crosses involving resistant hexaploid wheat genotypes when tested with $P$. tritici-repentis race 5 showed a resistant reaction (Table 4). Individual plant data were confirmed by screening $F_{2: 3}$ families of each of the $R / R$ crosses and all the families were resistant confirming that all four resistant sources possessed the same gene for resistance to chlorosis induced by $P$. tritici-repentis race 5 (Table 5). All the $F_{1}$ and $F_{2}$ plants and $F_{2: 3}$ families of the inter-specific cross between the resistant tetraploid (T. turgidum \#283) and the resistant hexaploid (Erik) sources showed a resistant reaction confirming that resistance to $P$. tritici-repentis race 5 in both tetraploid and hexaploid wheat were controlled by the same gene (Tables 4 and 5).

The genetic studies with $P$. tritici-repentis race 5 between susceptible genotypes Coulter (tetraploid) and Katepwa (hexaploid) gave interesting results. Coulter is susceptible to necrosis while Katepwa is susceptible to chlorosis caused by $P$. tritici-repentis race 5 (Table 1). All $F_{1}$ plants of the cross Coulter/Katepwa were susceptible showing only necrotic symptoms. Plants of the $F_{2}$ generation of this cross segregated for both necrosis and chlorosis. Rating plants for both necrosis and chlorosis components separately are error prone and hence disease scoring for resistant and susceptible (necrosis and/or chlorosis) reaction was performed. The $\mathrm{F}_{2}$ generation of this inter-specific S/S cross segregated in a 3 resistant:13 susceptible ratio indicating different genes control susceptibility to $P$. tritici-repentis race 5 in this cross (Table 4). The $F_{2: 3}$ families of this cross segregated for 1 homozygous resistant:15 susceptible (homozygous and hetero- zygous families) confirming different genes control susceptibility to necrosis (tetraploid) and chlorosis (hexaploid) caused by $P$. tritici-repentis race 5 in this cross (Table 5).

\section{DISCUSSION}

The identification and differentiation between the two distinct symptoms, tan necrosis and chlorosis, induced by $P$. triticirepentis on susceptible wheat cultivars has led to reliable and accurate assessment of resistance and susceptibility (14,22). Determination of the genetics of resistance to tan spot was further enhanced by the identification of $P$. tritici-repentis races inducing either necrosis or chlorosis symptoms and the development of the necrosis-chlorosis model of tan spot $(14,15)$. In the last two decades, various genetic studies have reported resistance to tan spot to be quantitatively $(4,7,18)$ or qualitatively $(11,12,19)$ inherited. However, accurate comparison of these conflicting studies cannot be made due to the lack of standardization of techniques such as method of inoculation, rating scales, symptoms studied, races/isolates used, and the environmental conditions for disease development.

The resistant parents studied were genetically diverse and included synthetic wheats and representative of three different species; T. aestivum, T. spelta, and T. turgidum; however, they all possessed the same resistance gene(s) for necrosis and chlorosis induced by $P$. tritici-repentis race 1 . Genetic and mapping studies reveal that the gene, tsn1, controlling resistance to necrosis caused by $P$. tritici-repentis races 1 and 2 is located on chromosome 5B $(1,6)$ and a major QTL controlling resistance to chlorosis caused by $P$. tritici-repentis race 1 is located on chromosome 1A (3). Tetraploid and hexaploid wheat possess both A and B genomes, which may explain the occurrence of the same resistance genes. The only prior interspecific genetic study (1) also demonstrated that the same single recessive gene controlled resistance to necrosis caused by the toxin Ptr ToxA, isolated from race 2 , in both tetraploid and hexaploid wheat.

Although recent studies by Tadesse et al. $(27,28)$ reveal that resistance to $P$. tritici-repentis race 1 is located on chromosomes $3 \mathrm{~A}$ and $\mathrm{D}$, similar novel results were not observed in this study.

TABLE 5. Reaction of $\mathrm{F}_{2: 3}$ or $\mathrm{F}_{2: 5}$ families of 11 wheat crosses to necrosis and chlorosis caused by Pyrenophora tritici-repentis race 5 evaluated in the greenhouse at University of Saskatchewan, Saskatoon (2002 to 2004) and North Dakota State University, Fargo (2004 to 2005) ${ }^{\mathrm{a}}$

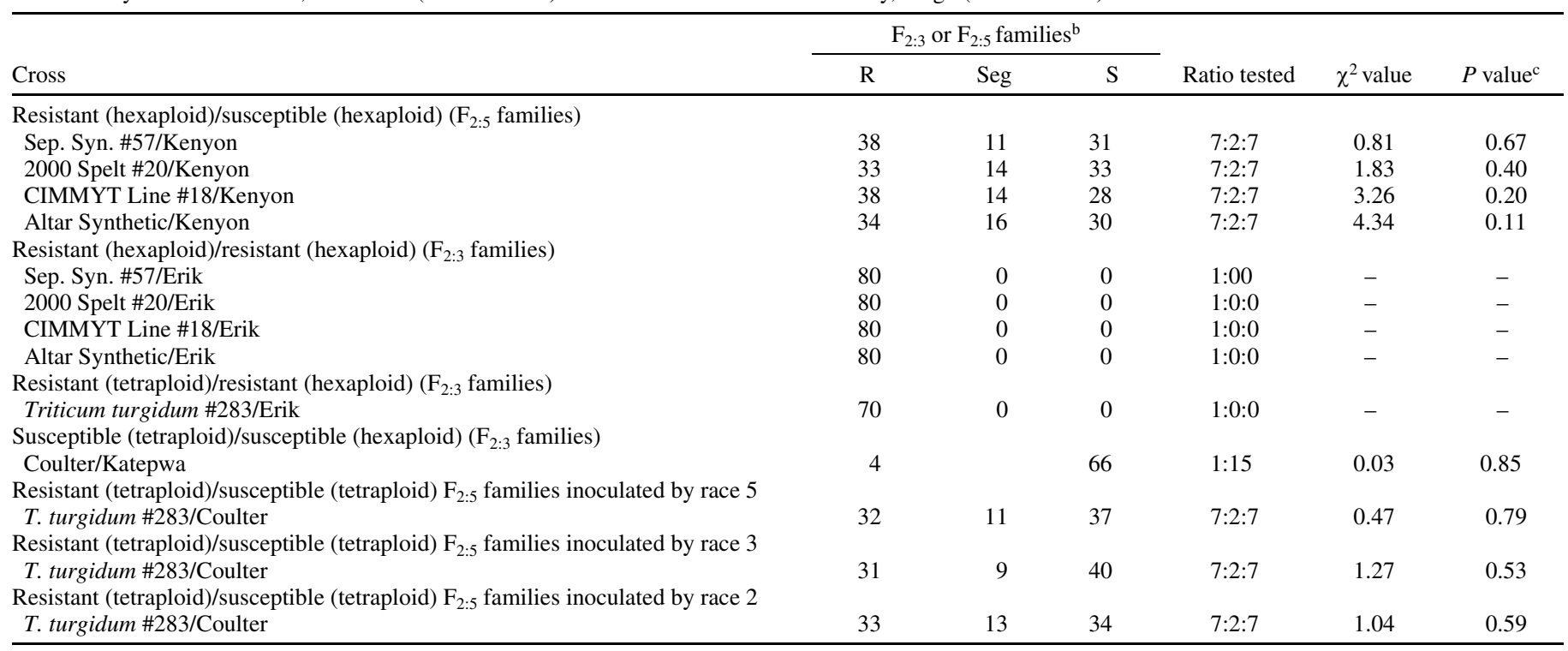

a Necrotic reaction of $\mathrm{F}_{2: 5}$ families of cross Triticum turgidum \#283/Coulter to races 2 and 3 is presented.

${ }^{b}$ Plants were rated on a 1-to-5 lesion-type rating scale with families having plants with ratings of 1 and 2 classified as resistant (R), ratings of 3 to 5 as susceptible (S) and those with both resistant and susceptible plants as segregating (Seg).

${ }^{\mathrm{c}}$ Probability of obtaining deviations from the expected ratio by chance alone. A probability value greater than 0.05 indicates that the observed population does not differ significantly from expected hypothesis. 
Differences in the findings of this study to that of Tadesse et al. $(27,28)$ could be due to differences in the resistant genotypes and isolates used and the environmental conditions of disease development and its assessment. Additionally, the virulence data provided by Tadesse et al. $(27,28)$ clearly indicates the isolates they had used were not race 1 even though they interpreted the isolates as $P$. tritici-repentis race 1 . Additional research needs to be conducted to resolve the difference in the findings of Tadesse et al. $(27,28)$ and other researchers $(1,6,12)$.

The finding of a single recessive gene controlling resistance in tetraploid wheat to tan necrosis induced by $P$. tritici-repentis race 5 was also observed by Gamba and Lamari (11). In this study a single dominant gene was found to control resistance to chlorosis induced by $P$. tritici-repentis race 5 in hexaploid wheat; however, previous findings reveal resistance to be controlled by a single recessive gene $(12,19)$ or to be quantitative in nature $(10)$. The mode of inheritance of resistance to chlorosis varies from recessive, partially dominant to completely dominant depending upon the parental genotypes (23). The expression of the chlorotic symptom of tan spot is continuous (14) and highly influenced by environmental conditions (23). Additionally, it is possible that Kenyon, the susceptible parents in all the crosses studied with $P$. tritici-repentis race 5, may possess a number of modifier genes which may contribute to the differing results.

The resistant parents analyzed in this study were genetically very diverse but the allelic studies for seedling resistance to $P$. tritici-repentis races 1 and 5 indicate that all the resistant sources possessed the same gene(s) for resistance to tan spot. These findings agree with earlier studies $(1,11,12)$ wherein different sources of resistance had no allelic differences for tan spot resistance. Although not all of these studies $(12,22,23)$ contained the resistant cultivar Erik, the allelic findings strongly suggest that the wheat gene pool possesses very narrow genetic diversity for resistance to tan spot and hence rigorous efforts should continue to seek new and different genes for resistance.

Lamari et al. (17) suggested that the wheat- $P$. tritici-repentis pathosystem conforms to the toxin model of gene-for-gene hypothesis originally proposed by Ellingboe (5). In this model, a compatible interaction between host plant and pathogen leads to susceptibility. The susceptibility interaction occurs due to the production of a toxin by the pathogen and the presence of a 'toxin-receptor' site in the host. If the presence of such a site is considered, the product of a susceptibility gene, then the resistance in the wheat-P. tritici-repentis pathosystem is due to lack of a susceptibility gene(s) rather than the presence of a resistance gene(s) $(17,22)$. This could be the reason why most studies have identified the same resistance gene(s) using the known races of $P$. tritici-repentis. Future allelic studies should be conducted among susceptible genotypes rather than resistant genotypes as in the wheat $-P$. tritici-repentis host pathosystem the susceptibility genes play major roles in the disease development.

Assuming hexaploid wheat-P. tritici-repentis pathosystem followed the toxin model of gene-for-gene hypothesis (17), prior genetic $(22,23)$, molecular $(3,6,7)$, and virulence $(16,17)$ studies indicate that the virulence of $P$. tritici-repentis race 1 is the addition of virulence of race 2 and race 3 . However, the single gene inheritance of resistance in the cross T. turgidum \#283/Coulter when challenged with $P$. tritici-repentis races 1,2 , and 3 indicates that in the case of tetraploid wheat $-P$. tritici-repentis host pathosystem the virulence of $P$. tritici-repentis race 1 is not the addition of virulence of race 2 and race 3 . In tetraploid wheat, race 1 causes necrosis similar to race 2 and the same gene controls resistance (11). Similar results were observed in this study. Although the segregation for chlorosis induced by $P$. triticirepentis race 1 in the cross T. turgidum \#283/Coulter was not observed, there was single gene segregation for resistance to necrosis induced by race 3 (21). Coulter is susceptible and $T$. turgidum \#283 is resistant to $P$. tritici-repentis races 1,2 , and 3 and hence if virulence of race 1 is addition of races 2 and 3 and tetraploid wheat- $P$. tritici-repentis follows the gene-for-gene hypothesis, then the cross T. turgidum \#283/Coulter should show two gene segregation when challenged with race 1 . However, a single gene segregation was observed in the cross $T$. turgidum \#283/Coulter indicating race 1 lacks the virulence factor present in race 3 . This is supported by the differential symptoms observed in tetraploid line 4B-160 to races 1 and 3 (11).

Friesen and Faris (10) mapped the resistance to chlorosis induced by $P$. tritici-repentis race 5 to the distal tip of chromosome $2 \mathrm{~B}$ in hexaploid wheat while Singh et al. (25) mapped the resistance to necrosis in tetraploid wheat to the long arm of chromosome 3B. Studying the interspecific cross between two susceptible genotypes Katepwa (chlorotic and hexaploid) and Coulter (necrotic and tetraploid), the genetic analysis indicates that there are two independent susceptibility genes for $P$. tritici-repentis race 5 , one for necrosis in tetraploid and the other for chlorosis in hexaploid wheat. Assuming wheat-P. tritici-repentis follows the gene-for-gene hypothesis, this genetic finding for the first time confirms that $P$. tritici-repentis race 5 possesses two virulence genes. The identification of multiple major genes for resistance to tan spot and no interaction among them indicates that in order to develop complete resistance to all races of $P$. tritici-repentis, wheat breeders need to incorporate all the resistance genes.

\section{ACKNOWLEDGMENTS}

Financial support from Saskatchewan Agriculture Development Fund, Saskatchewan, Canada, Minnesota Wheat Research and Promotion Council, Minnesota, and State Board of Agricultural Research and Education, North Dakota, is gratefully acknowledged. We thank J. Feng, S. Singh, and R. Babonich for their assistance throughout this study.

\section{LITERATURE CITED}

1. Anderson, J. A., Effertz, R. J., Faris, J. D., Francl, L. J., Meinhardt, S. W., and Gill, B. S. 1999. Genetic analysis of sensitivity to a Pyrenophora tritici-repentis necrosis inducing toxin in durum and common wheat. Phytopathology 89:293-297.

2. De Wolf, E. D., Effertz, R. J., Ali, S., and Francl, L. J. 1998. Vistas of tan spot research. Can. J. Plant Pathol. 20:349-370.

3. Effertz, R. J., Meinhardt, S. W., Anderson, J. A., Jordahl, J. G., and Francl, L. J. 2002. Identification of a chlorosis-inducing toxin from Pyrenophora tritici-repentis and the chromosomal location of an insensitivity locus in wheat. Phytopathology 92:527-533.

4. Elias, E., Cantrell, R. G., and Horsford, R. M., Jr. 1989. Heritability of resistance to tan spot in durum wheat and its association with other agronomic traits. Crop Sci. 29:299-304.

5. Ellingboe, A. H. 1976. Genetics of host-parasite interactions. Pages 761778 in: Encyclopedia of Plant Physiology. Vol. 4. Physiological Plant Pathology. R. Heitefuss, and P. H. Williams, eds. Springer-Verlag, New York.

6. Faris, J. D., Anderson, J. A., Francl, L. J., and Jordahl, J. G. 1996. Chromosomal location of a gene conditioning insensitivity in wheat to a necrosis-inducing culture filtrate from Pyrenophora tritici-repentis. Phytopathology 86:459-463.

7. Faris, J. D., Anderson, J. A., Francl, L. J., and Jordahl, J. G. 1997. RFLP mapping of resistance to chlorosis induction by Pyrenophora triticirepentis. Theor. Appl. Genet. 94:98-103.

8. Faris, J. D., and Friesen, T. L. 2005. Identification of quantitative trait loci for race-nonspecific resistance to tan spot in wheat. Theor. Appl. Genet. 111:386-392

9. Fernandez, M. R., DePauw, R. M., Clarke, J. M., and Fox, S. L. 1998. Discoloration of wheat kernels by Pyrenophora tritici-repentis. Can. J. Plant Pathol. 20:380-383.

10. Friesen, T. L., and Faris, J. D. 2004. Molecular mapping of resistance to Pyrenophora tritici-repentis race 5 and sensitivity to Ptr ToxB in wheat. Theor. Appl. Genet. 109:464-471.

11. Gamba, F. M., and Lamari, L. 1998. Mendelian inheritance of resistance to tan spot (Pyrenophora tritici-repentis) in selected genotypes of durum wheat (Triticum turgidum). Can. J. Plant Pathol. 20:408-414.

12. Gamba, F. M., Lamari, L., and Brûlé-Babel, A. 1998. Inheritance of racespecific necrotic and chlorotic reactions induced by Pyrenophora triticirepentis in hexaploid wheats. Can. J. Plant Pathol. 20:401-407. 
13. Hanson, W. D. 1959. Minimum family sizes for the planning of genetic experiments. Agron. J. 51:711-715.

14. Lamari, L., and Bernier, C. C. 1989. Evaluation of wheat lines and cultivars to tan spot (Pyrenophora tritici-repentis) based on lesion type. Can. J. Plant Pathol. 11:49-56.

15. Lamari, L., and Bernier, C. C. 1989. Toxin of Pyrenophora triticirepentis: Host specificity, significance in disease, and inheritance of host reaction. Phytopathology 79:740-744.

16. Lamari, L., Sayoud, R., Boulif, M., and Bernier, C. C. 1995. Identification of a new race in Pyrenophora tritici-repentis: Implications for the current pathotype classification system. Can. J. Plant Pathol. 17:312-318.

17. Lamari, L., Strelkov, S. E., Yahyaoui, A., Orabi, J., and Smith, R. B. 2003. The identification of two new races of Pyrenophora tritici-repentis from the host center of diversity confirms a one-to-one relationship in tan spot of wheat. Phytopathology 93:391-396.

18. Nagle, B. J., Frohberg, R. C., and Hosford, R. M., Jr. 1982. Inheritance of resistance to tan spot of wheat. Pages 40-45 in: Tan Spot of Wheat and Related Diseases Workshop. R. M. Hosford, Jr., ed. North Dakota State University, Fargo, ND.

19. Orolaza, N. P., Lamari, L., and Ballance, G. M. 1995. Evidence of a hostspecific chlorosis toxin from Pyrenophora tritici-repentis, the causal agent of tan spot of wheat. Phytopathology 85:1282-1287.

20. Shabeer, A., and Bockus, W. W. 1988. Tan spot effects on yield and yield components relative to growth stage in winter wheat. Plant Dis. 72:599-602,

21. Singh, P. K., Gonzalez-Hernandez, J. L., Mergoum, M., Ali, S., Adhikari, T. B., Kianian, S. F., Elias, E. M., and Hughes, G. R. 2006. Identification and molecular mapping of a gene in tetraploid wheat conferring resistance to Pyrenophora tritici-repentis race 3. Phytopathology 96:885-889.

22. Singh, P. K., and Hughes, G. R. 2005. Genetic control of resistance to tan necrosis induced by Pyrenophora tritici-repentis, races 1 and 2, in spring and winter wheat genotypes. Phytopathology 95:172-177.

23. Singh, P. K., and Hughes, G. R. 2006. Inheritance of resistance to the chlorosis component of tan spot of wheat caused by Pyrenophora triticirepentis races 1 and 3. Euphytica 152:413-420.

24. Singh, P. K., Mergoum, M., Ali, S., Adhikari, T. B., Elias, E. M., and Hughes, G. R. 2006. Identification of new sources of resistance to tan spot, Stagonospora nodorum blotch, and Septoria tritici blotch of wheat. Crop Sci. 46:2047-2053.

25. Singh, P. K., Mergoum, M., Gonzalez-Hernandez, J. L., Ali, S., Adhikari, T. B., Kianian, S. F., Elias, E. M., and Hughes, G. R. 2006. Genetics and molecular mapping of resistance to necrosis inducing race 5 of Pyrenophora tritici-repentis in tetraploid wheat. Mol. Breed. 21:293-304.

26. Strickberger, M. W. 1985. Genetics. 3rd edition, MacMillan Publishing Company, New York.

27. Tadesse, W., Hsam, S. L. K., Wenzel, G., and Zeller, F. J. 2006. Identification and monosomic analysis of tan spot resistance genes in synthetic wheat lines (Triticum turgidum L. $\times$ Aegilops tauschii Coss.). Crop Sci. 46:1212-1217.

28. Tadesse, W., Hsam, S. L. K., and Zeller, F. J. 2006. Evaluation of common wheat (Triticum aestivum L.) cultivars for tan spot resistance and chromosomal location of a resistance gene in cultivar 'Salamouni'. Plant Breed. 125:318-322. 